\title{
The Empirical Implications of Privacy-Aware Choice
}

\author{
RACHEL CUMMINGS, Northwestern University \\ FEDERICO ECHENIQUE, California Institute of Technology \\ ADAM WIERMAN, California Institute of Technology
}

\begin{abstract}
This paper initiates the study of the testable implications of choice data in settings where agents have privacy preferences. We adapt the standard conceptualization of consumer choice theory to a situation where the consumer is aware of, and has preferences over, the information revealed by her choices. The main message of the paper is that little can be inferred about consumers' preferences once we introduce the possibility that the consumer has concerns about privacy. This holds even when consumers' privacy preferences are assumed to be monotonic and separable. This motivates the consideration of stronger assumptions and, to that end, we introduce an additive model for privacy preferences that does have testable implications.
\end{abstract}

Categories and Subject Descriptors: J.4 [Social and Behavioral Sciences]: Economics

Additional Key Words and Phrases: Privacy; revealed preference

A full version of this paper is available at: http://arxiv.org/abs/1401.0336

This work was supported by NSF grants 1101470, 1216006, and CNS-1254169, as well as BFS grant 2012348 and the Charles Lee Powell Foundation.

Author's addresses: Rachel Cummings, Electrical Engineering and Computer Science Department, Northwestern University, Evanston, IL 60208; Federico Echenique, Division of the Humanities and Social Sciences, California Institute of Technology, Pasadena, CA 91125; Adam Wierman, Department of Computing and Mathematical Sciences, California Institute of Technology, Pasadena, CA 91125.

Permission to make digital or hard copies of part or all of this work for personal or classroom use is granted without fee provided that copies are not made or distributed for profit or commercial advantage, and that copies bear this notice and the full citation on the first page. Copyrights for third-party components of this work must be honored. For all other uses, contact the owner/author(s). Copyright is held by the author/owner(s).

EC'14, June 8-12, 2014, Stanford, CA, USA.

ACM 978-1-4503-2565-3/14/06.

http://dx.doi.org/10.1145/2600057.2602830 